\title{
Participation for sustainability: why looking back to design the future?
}

\author{
E. Giorgi, T. Cattaneo \& G. D. Manzoni \\ Department of Civil Engineering and Architecture, \\ University of Pavia, Italy
}

\begin{abstract}
As demonstrated by the Italian experience of Olivetti in Ivrea (1950-1960), by the design-philosophy of Giancarlo De Carlo (1973), and as argued by Saskia Sassen (2006, 2014), citizen-centred design and sharing practices represent the main path to a sustainable future. The aim of this research is to define the relations between historical and contemporary forms of participation in architecture, by investigating three key concepts: design, living, and programs. Ten contemporary projects and three historical typologies were analysed; these are characterized by freedom of participation: the Chinese "Tulou", the Israeli "Kibbutz", and the Italian rural farm "Cascina". The work is based on a comparative analysis of historical and contemporary groups composed by the chosen case studies. The projects of both groups have been compared on the basis of their social, functional, programmatic, spatial, and sharing organization. The output is a cloud of concepts that put in relation past and contemporary experiences with participation (in terms of design, living, and programs) for a sustainable development.

Keywords: communities, comparison analysis, contemporary and historical.
\end{abstract}

\section{Introduction}

The purpose of this research is to identify patterns in historical cases of community living and its contemporary manifestation given increasing interest by the scientific community and public opinion. The interest in community or shared living is due to the strong belief that this is one of the driving forces of communal for architecture, and for the whole of society, to face the contemporary problems of social and environmental sustainability. A better knowledge of history could lead to good practice and a better understanding of shared living, which is present 
in all the living traditions of the past. Albeit, with several differences in terms of culture, social composition, environmental context, and historic background, we can always attribute to the sharing of spaces and activities a central role in the social life of all the cultures of the past.

The research is based on a study of comparable case studies on sustainable shared living, gathered in two groups, "historical" and "contemporary". In the course of the study, data about a variety of relevant variables collected to identify the relevant factors that could represent a possible explanation for the differences between the groups. Each project has been studied through five key design strategies and organizational principles in order to define the core of the projects and to summarize them in semantic datasheets, presented in this paper. According to the same principle, through the five key design strategies, the two groups have been analysed using a correlational approach that uses a categorical measurement to highlight the variables of interest, sorted into discrete verbal or nominal categories. Three keywords are used for the comparison: design, living, and programs. These are three core concepts for communitarian housing, which are able to define the principles that link historical and contemporary forms of participation in architecture.

\section{Historical cases}

To guarantee the widest possible spectrum of representativeness, we decided to consider three forms of shared living (the Chinese Tulou, the Italian Cascina and the Jewish Kibbutz), which, even though emerged at different cultures and historical periods, are all characterized by voluntary participation and by historical perspectives. After our analysis, we can affirm that they are the result of a participatory building process. As argued by De Carlo [1], before industrialization, "the idea of how to organize and give shape to the space was a common heritage. [...] Many people participated in a widespread culture of living". In fact, Cascina (Table 2) and Tulou (Table 1) are typical rural settlements that combine living and agriculture, defined by several centuries of practice and living, and developed around the activities of men in their territories. Instead, the Kibbutz (Table 3), even though it is an experience of the 20th century, must be considered in the historical group because it is a result of traditional processes.

We can define the essence of the historical cases as being characterized by participation in living and production. These are sustainable actions that inform design of the territory, its organization, and the architectural space. 
Table 1: $\quad$ Tulou - Fujian Province, China, 11th-20th century [2].

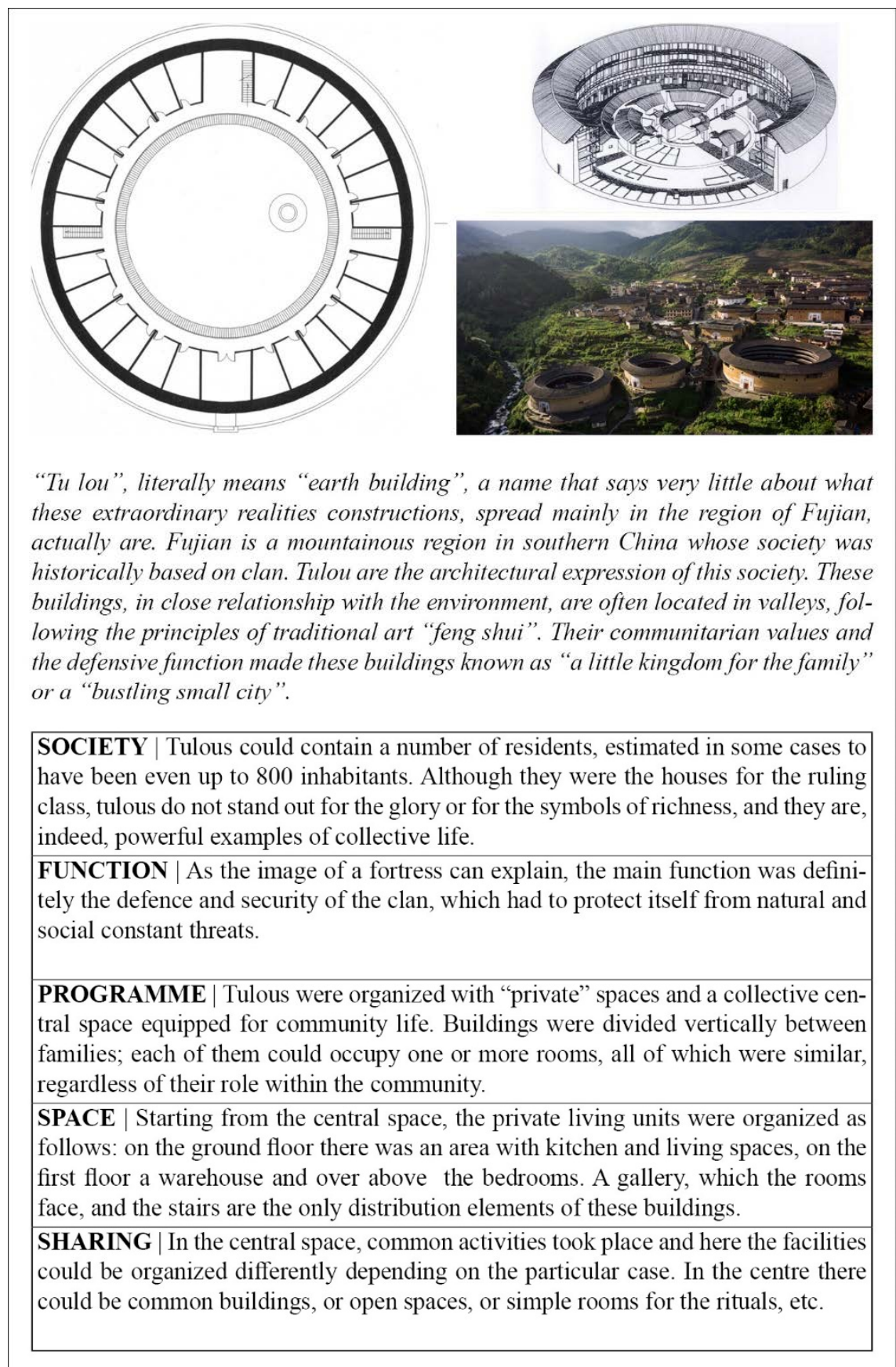


Table 2: Cascina - Lombardy Region, Italy, 15th-20th century [3].
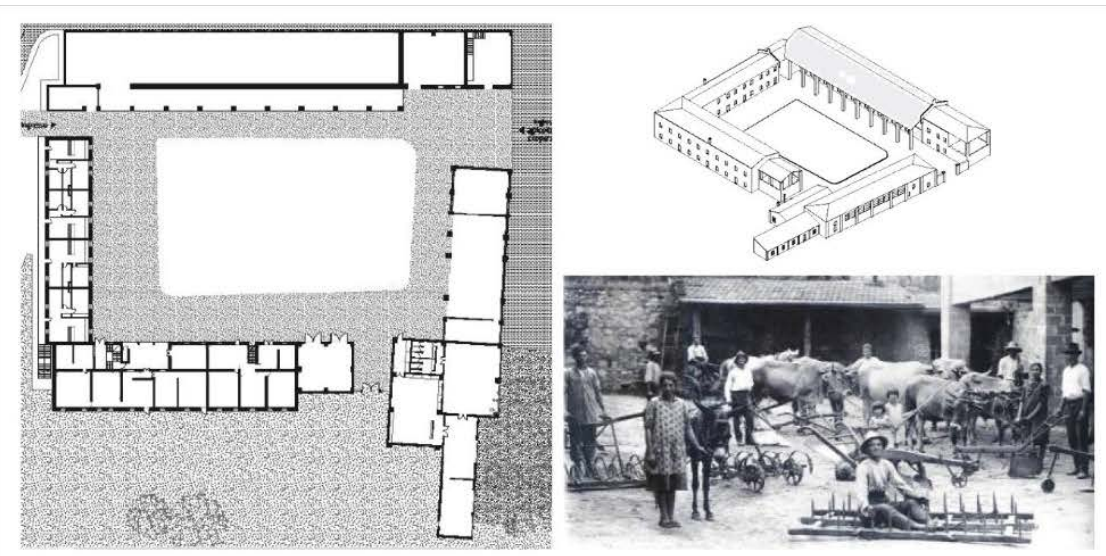

Cascina is a typical agricultural settlement in the northern part of Italy. The widest dissemination of the farms took place in the 18th century. In the capitalist organization of agriculture, Cascinas has represented during history the perfect elements for the rationalization of agricultural production. These buildings are isolated in the rural territory, emerging as a sort of independent small settlement, with a defined typology, functional organization, and social structure.

SOCIETY | Cascina could contain an average of 4 to 20 families. People who lived in these buildings were farmers, whose working activities were organized by the owner. Each farmer participated to the life and agricultural production of the whole community through a specialized job. Thus, the typology and spaces of the Cascina were built to correspond to the functional and social structure.

FUNCTION | The main function of the Cascina was farming. Inside the farmhouse there were a wide range of productive facilities, such as stables, barns, silos, dairies, wells, fountains, ovens, warehouses, mills, houses and sometimes taverns or a small church, even a school, gathered together in exemplary architecture.

PROGRAMME | The rural settlement was owned by a single person who, usually, did not live in the Cascina and, as a result, did not participate in the life of the community. The management of the Cascina was usually delegated to a head-farmer who organized the working activities of the farmers and the shared life of the families, in terms of living, production, education, and leisure.

SPACE | Usually, the plan of this typology of building was organized around a courtyard, according to these five concepts:

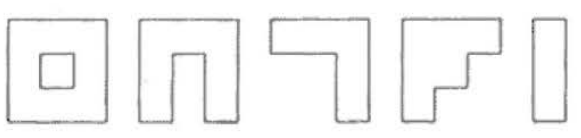

SHARING | The sharing spaces were represented by the courtyard or covered veranda, which were the common areas, where the farmers held meetings, parties or spent time together. In the other bindings, all around the courtyard, there were the agricultural facilities and the farmers' houses. 
Table 3: $\quad$ Kibbutz - Israel, 20th century [4].

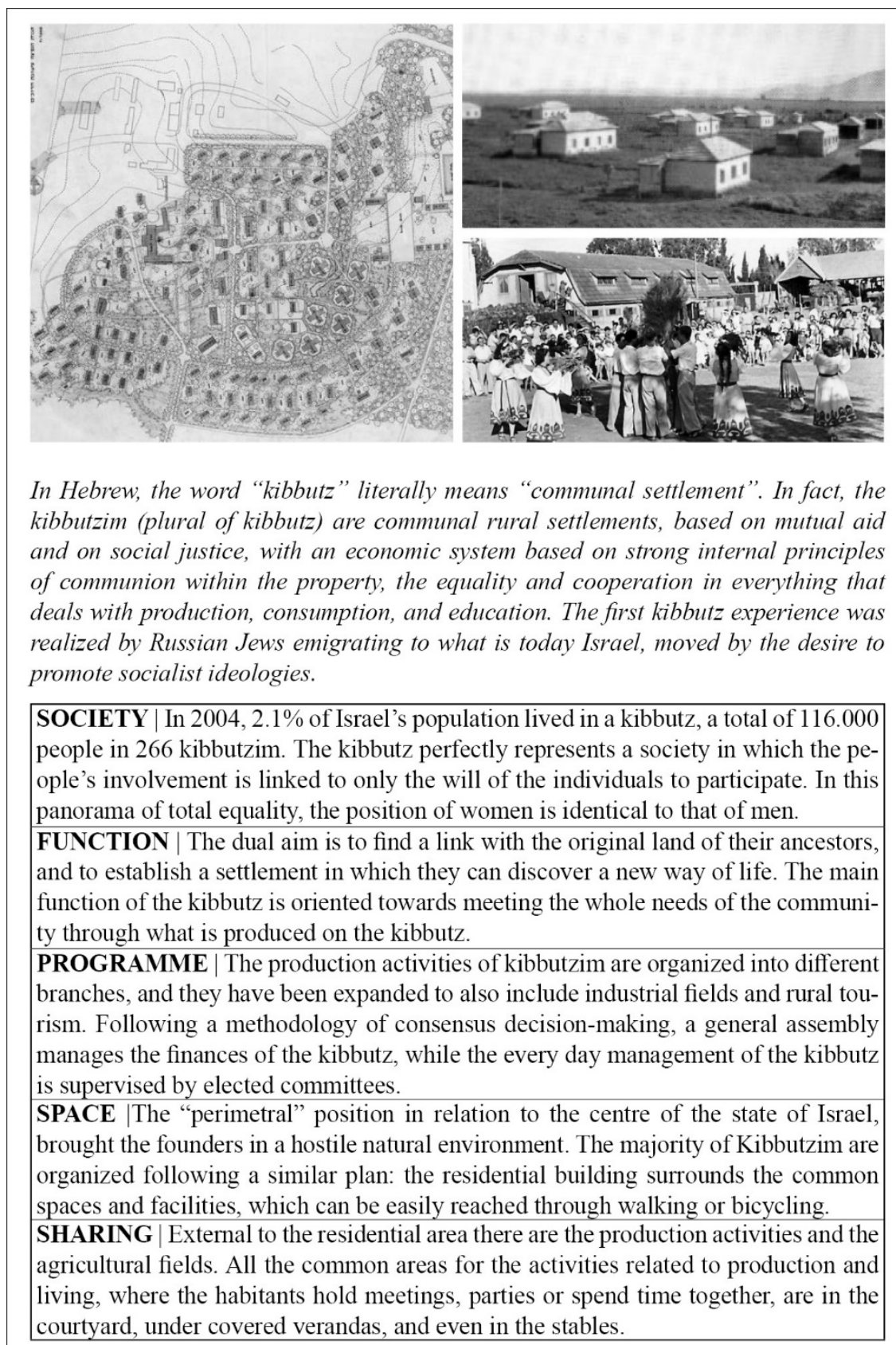




\section{Contemporary cases}

In the last decades, several reactions developed against the contemporary challenges facing traditional community and society. These reactions were not driven only by political reasons (as the experiences of the communes), but had stronger motivations in the human need for social relations and community living $[5,6]$. In this context, there is a need to develop a new system of values, enabling us to deal at a human scale with those challenges, so that architecture is able to develop alternatives to the conventional way of living [7]. In this way, as was the case with respect to the past experiences, also the contemporary choice of living a shared life is not a romantic decision; but is a rational choice. The syntheses of nine of the 30 data sheets of the studied projects are presented below. For the selection of the 30 projects that constitute the "contemporary" group and from which the first conclusions derive, it was decided to represent the broadest possible series of cases in terms of geographical distribution, dimensions, and environmental and social contexts. Shared living has a lot of remarkable features; nevertheless, the chosen cases have in common the fact that they have a strong element of voluntariness with respect to the decision to participate in the form of life and community management. The private homes contain all the features of conventional homes, but residents also have access to extensive common facilities such as open spaces, courtyards, playground, and a common house. It is interesting to highlight that all the considered projects have shared spaces, a relation with the social context in which they fit, connections with small-scale productive activities, and are respectful of their environment. The outcome of an environmentally sustainable approach can lead to restoring social sustainability and of regaining a human-scale way of living. We might even envision that a humanistic design, which these projects are inspired by, could serve as a model for a social and environmentally sustainable housing today. We must not forget, in fact, as these two aspects are intrinsically linked (as suggested by the Italian experience of Olivetti [8] and, more recently, in the encyclical "Laudato si" by Pope Francis [9]. We therefore cannot propose the same solutions as in the past. Rather, we should learn from the past in order to find new solutions to these problems. It is a matter of giving a contemporary response to an ancient need for community living, which has been lost due to increased globalisation. Hence, the contemporary shared life must be considered revolutionary, at least for our everyday existence. In this way, sharing succeeds in crossing the limits of family or work ties and in creating innovative levels of community. 
Table 4: Wind Song - Langley, Canada, 1996, DYS Architects [10].

\begin{tabular}{|l|}
\hline SOCIETY | 34 families combine an urban and rural lifestyle in a \\
well-preserved natural environment, sustaining their home-schoo- \\
ling practices.
\end{tabular}

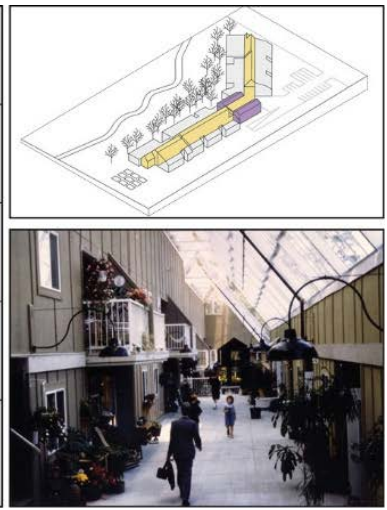

Table 5: $\quad$ LILAC - Leeds, UK, 2013, White Design Associates [11].

SOCIETY | LILAC (Low Impact Living Affordable Community) is a self-developed community composed of 20 families who want to live in an eco-friendly environment.

FUNCTION | An ecological approach is the main community goal: one pond, the shared garden and a children's playground are the core functions of the community.

PROGRAMME $\mid$ The ecological approach is accompanied by the life-style of the co-houses, in which the residents sign a pledge which commits them to the eco-philosophy of the community.

SPACE $\mid 20$ houses organized around a common green space, which is meant to reduce the community's footprint. The courtyard arrangement increases the opportunities for socializing and sharing. SHARING | LILAC has a strong level of sharing life also with respect to the wider local community. The common house located at the main gate hosts events and permits access to the facilities.

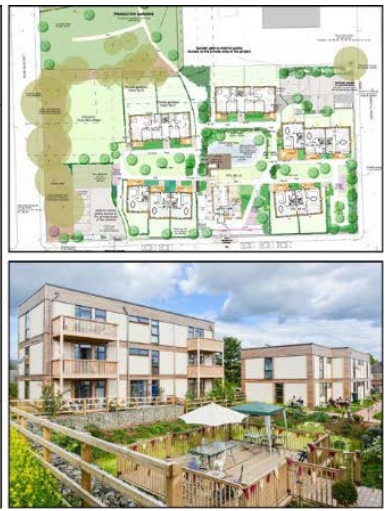

Table 6: $\quad$ Munksoegard - Roskilde, Denmark, 2000 [12].

SOCIETY | 5 different social types comprise this community: single owner families; co-operative associations; young people on rent; older people and people of all ages renting.

FUNCTION | The main residential function is oriented to strongly combine sustainable life and sharing experiences through, e.g., waste recycling, sustainable construction techniques, etc.

PROGRAMME $\mid$ There are five committees that manage the operations and represent the five communities, whose activities are mainly addressed toward sustainability and social production.

SPACE | The buildings are organized into the shape of five horseshoes, in a radial disposition around an old common farmhouse. Every community has its own common spaces and facilities.

SHARING | The central common house supports many common activities: cafe, vegetable shop, gift shop, office space for rent, sleepover room for rent, workshops, and storage spaces for rent.

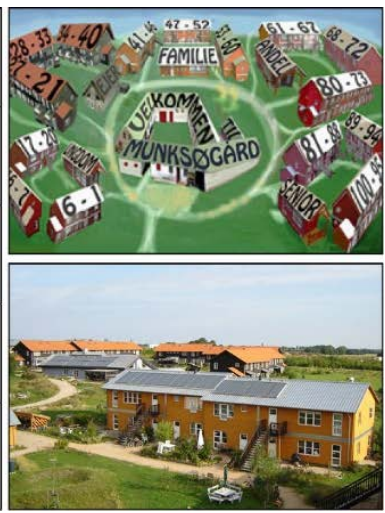


Table 7: $\quad$ Talponia - Ivrea, Italy, 1975, Gabetti and Isola [13].

SOCIETY | This complex was intended to host the youngest workers and employees of Olivetti, one of the most important Italian industries, which is the promoter of the project.

FUNCTION | The main residential function represents a symbol of the general political vision of the industrialist Adriano Olivetti, who tried to place the worker, as a person, at the centre of production.

PROGRAMME | The dream was to reconnect the workers with the nature, allowing a life-style which combines culture, environment, sociality, and work in shared activities and facilities.

SPACE $\mid 82$ small semi-underground house units are distributed with a semi-circular shape around a central green hill. On the roof, a common green space follows the building's shape.

SHARING | Public gardens and public spaces host the common activities and the shared facilities, as it typically happens in an Italian urban space.

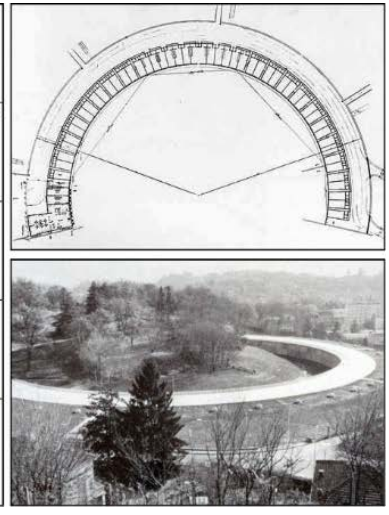

Table 8: $\quad$ Old Women Cohousing - Barnet, UK, 2015, PTEArchitect [14].

SOCIETY | Almost twenty women between 50 and 80 years of age, coming from different life experiences, who do not want to live alone, comprise the social group of this co-housing project.

FUNCTION | The main function comes from the willingness to offer and receive mutual support and to live in an environment which fosters exchanges and relations.

PROGRAMME $\mid$ A long phase of participatory design has come to define this program for a community suitable for elderly people and based on sustainability and respect for the urban context.

SPACE $\mid 20$ apartments with common spaces, such as workshops and guestrooms, are organized in a restored complex which characterizes the central courtyard, the place for meetings and sharing activities.

SHARING OWCH wants to become a resource for the local community and reference for elderly people; monthly meetings are organized to explain the aims of this project.

Table 9: $\quad$ Pioneer Valley - Amherst, USA, 1994, Kraus-Fitch Arch [15].

SOCIETY | Pioneer Valley was the first co-housing neighbourhood in the Eastern United States and includes 32-units of energy efficient housing with a 5,000 sq. $\mathrm{m}$. of shared spaces.

FUNCTION | Building orientation, super-insulation, partial self-production of food from the common garden guarantee the sustainable approach of the community.

PROGRAMME | The programme is a work in community progress, continuing and improving their values and goals, based on social and environmental sustainability.

SPACE | Single houses are spread around a common house, which can host several shared facilities, such as a multifunctional room, children's play room, library, and one on-site home offices.

SHARING | The complex is based on the willingness to support community life, providing well structured interactions; e.g., the 2 or 5 shared dinners per week or the walking commute, etc.
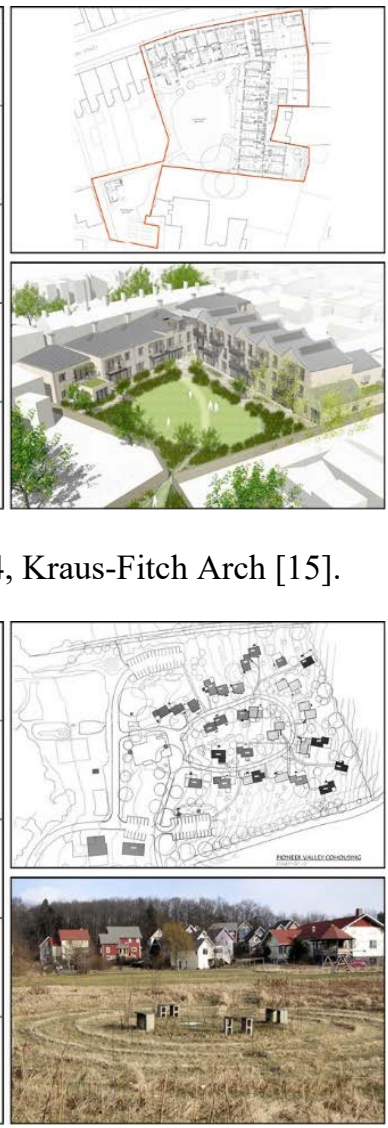
Table 10: Tulou Housing - Guangzhou, China, 2009, Urbanus [16].

SOCIETY | This urban community is comprised of low-income families, many of whom are migrant workers, and it proposes a new typology of housing.

FUNCTION | Reinterpreting the historical tulou typology, this project offers affordable housing, recreated not just by the tulou's shape, but also by a communitarian attitude .

PROGRAMME | The attention to social problems is supported by careful attention being paid to the common activities and spaces, but also by considerations taken with respect to the building orientation. SPACE | The 220 apartment housing complex is a clear reinterpretation of the traditional Hakka buildings, creating an intimate atmosphere by striking a good balance between private and public spaces SHARING | Besides the residential private spaces, the complex hosts several complementary functions and a variety of communal and public spaces.

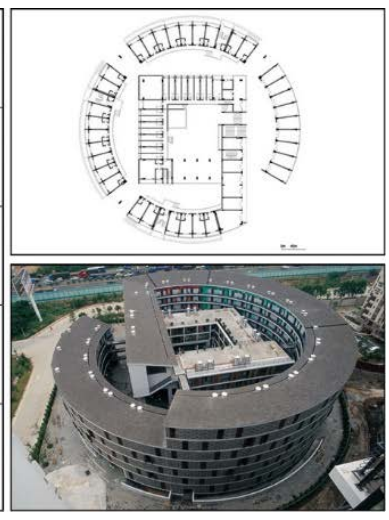

\section{Table 11: Wencun Village - Guangdong, China, 2016, Wang Shu [17].}

SOCIETY | The regeneration of the Wencun Village is devoted to give new social life to the rural community, affected by social depletion caused by the Chinese rapid urbanization.

FUNCTION | The project's goal is to reinforce the existing functions, with the aim to rediscover a rural life, featuring traditional knowledge, culture, social harmony, and environmental respect.

PROGRAMME | The life in the village is organized by the inhabitants, according to their needs and private lives, and developed within a wider set of opportunities for social participation and collaboration. SPACE | 14 houses and several public shared facilities compose a dense urban fabric, which coheres with the vernacular architecture and the urban scheme of the rural village.

SHARING | The inhabitants find new opportunities to share facilities and activities, according to the traditional common life of the village, in a renewed urban space.

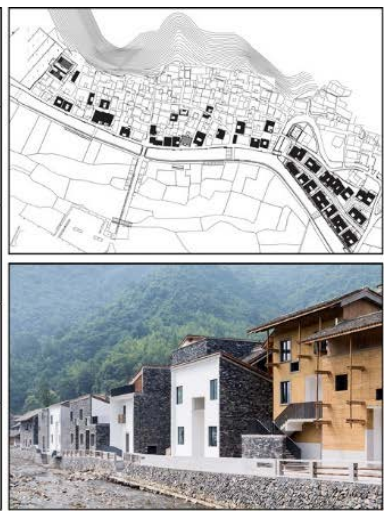

\section{Table 12: Rural community - Portugal, 2009, Atelier da Bouça. [18]}

SOCIETY | Boalhosa was an agricultural colony in the 1950's, restored with the aim of settling a new eco-community, combining landscape quality and social housing in a rural context.

FUNCTION | The residential function is combined with the Environmental Observatory, which develops research activities on landscape protection.

PROGRAMME | Encouraging the development/supply of essential services for the territory, the project improves the quality of life of the local population in non-urban locations.

SPACE $\mid$ New spaces have been added to the existing buildings, facing the challenge of a dense wooden context, while the existing buildings has been reorganized to host new functions.

SHARING | It creates spaces and essential facilities in the field of social services, giving priority to the recovery of the architectural and natural heritage. The environment is an active side of the shared life.

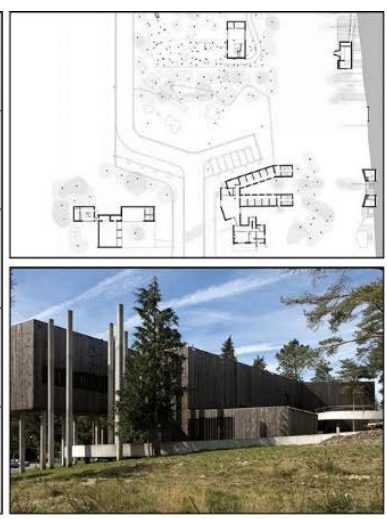




\section{Comparison}

Considerations arising from the study of the projects outlined above have made it possible to define the common characteristics of the two groups. These were described through the five key design strategies and variables/organization principles.

The results obtained in this phase are described in Figure 1 below. The next step, also shown in the figure, was the semantic comparison between the two groups, in which the ten resulting concepts have been compared, producing concepts which compare the two groups.

The results have been collected in a semantic cloud organized according to three keywords, in order to allow an easier comparison to be made between the two groups. Design: the inhabitants collaborate to plan the spaces and to define the communitarian organization. Living: the inhabitants share spaces and activities for residential and connected purposes. Programs: the inhabitants habitually manage their shared life through different decision-making processes. The comparative analysis has helped to clarify the relationship between two or more naturally occurring variables [19].

\section{HISTORICAL CASES}

SOCIETY | Clear and fixed roles for the residents inside the community, with the organization depending on the cultural social rules.

FUNCTION | Residential function is connected to defensive aims and to productive activities that are strictly linked with the territory.

PROGRAMME | Activities are organized according to systematic schedules and customs, held regularly on the basis of temporary occurrences.

SPACE $\mid$ Private and common spaces, present in variable ratios, are combined with clear and different typologies adapting to the environment.

SHARING | High levels within the community, in terms of education, assets, production and residential activities.

\section{CONTEMPORARY CASES}

SOCIETY | The organization strongly depends on the purpose of the community, which often aims to create a best practice island.

FUNCTION | Support the living, promoting conditions to help the residents in facing the troubles of the contemporaneity.

PROGRAMME | Management and decisions taken directly by the residents or entrusted to representatives, according to the community's policies.

SPACE | Several typologies, in new or restored complexes, allow shared life in with private spaces always guaranteed.

SHARING | The quality strongly depends by the general aim of the community; usually it regards complementary activities to the residential one.

Figure 1: Comparison analysis.

\section{Conclusions}

From the comparison, we were able to identify consistent relationships between historical and contemporary cases. We can conclude what determines the idea of 
participation in creating community living or shared spaces. First of all, it is defined by a strong relationship between the individual and the environment, including the physical environment, the territory and the landscape, the social environment and the collective ties. With this perspective, the voluntary participation in the life of the community is an opportunity to redefine one's own position in the environment. For this reason, we can say that the communitarian approach to living is an extraordinary cultural practice aimed at complete sustainability.

According to this, we can claim that participation in shared life conveys $a$ cultural, free choice of living in a close relationship with the environment, developing activities and collaborations in shared and common spaces in order to achieve a complete sustainability.

It is necessary to underline that, in addition to these concepts, which are shared between the two groups, other concepts are specific to just one group. In particular, we can highlight how some of these concepts are typical just of past experiences because they answer to specific features of the past (for example, cycles), or because they have not yet been incorporated into the design of contemporary realities in terms of best practices. Some features are also present only in contemporary experiences because they meet the specific needs of the contemporary world (e.g. environmental sustainability). This consideration could provide the basis for further research to investigate the evolution of shared living, by highlighting the elements of change.

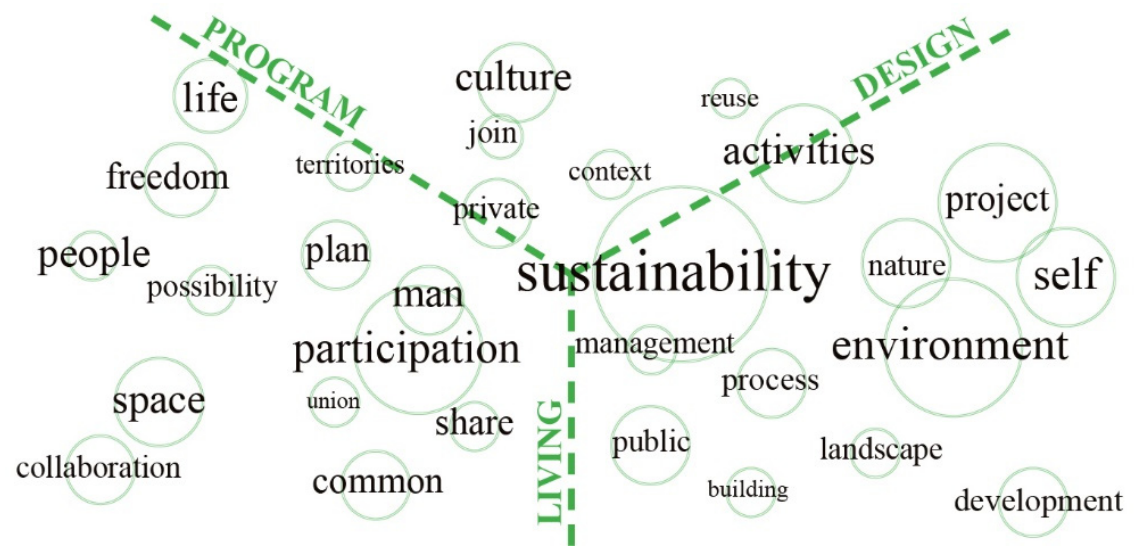

Figure 2: Semantic cloud of concepts.

\section{References}

[1] De Carlo, G., Sulla progettazione partecipata. Avventure urbane. Progettare la città con gli abitanti, eds Scavi M., et al., Elèuthera: Milan, p. 244, 2002. (Translation by the author.)

[2] UNESCO Advisory Body Evaluation, Fujian Tulou. http://whc.unesco.org /en/list/1113, 2016. 
[3] Crotti, S., Bertelli, G., Reggio, M. \& Vanetti, D., Abaco degli edifici nel Parco del Ticino, Alinea Editrice: Firenze, pp. 12-31, 2008.

[4] The Kibbutz Movement, Facts and figures, Research and Documentation Center of the Kibbutz Movement; Central Bureau of Statistics (C.B.S.) of the State of Israel. www.kibbutz.org.il/eng/articles/040421_2002_facts. PDF.

[5] Sassen, S.A., Sociology of Globalization, W.W. Norton: New York, pp. 1542, 2007.

[6] Sassen, S., Expulsions: Brutality and Complexity in the Global Economy, Harvard University Press: Cambridge, pp. 149-210, 2014.

[7] De Carlo, G., L'architettura della partecipazione, Quodlibet Abitare: Macerata, p. 55, 2013.

[8] Olivetti, A., Il cammino della comunità, Comunità Editrice: Ivrea, pp. 2123, 2013.

[9] Pope Francis, Encyclical Letter Laudato Si' of the Holy Father Francis On Care For Our Common Home, Vatican Press: Rome, p. 104, 2015.

[10] Wind Song Cohousing, www.windsong.bc.ca. Accessed on: 8 Aug. 2015.

[11] LILAC Cohousing, www.lilac.coop. Accessed on: 10 Aug. 2015.

[12] Munksoegaard Community, www.munksoegaard.dk. Accessed on: 10 Aug. 2015.

[13] Guerra, A., Isola A. \& Morresi, M., Gabetti e Isola: opere di architettura, Electa: Milano, pp. 67-75, 1996.

[14] Old Women Cohousing, www.owch.org.uk. Accessed on: 12 Jul. 2015.

[15] Pioneer Cohousing, www.cohousing.com. Accessed on: 5 Aug. 2015.

[16] Urbanus, www.urbanus.com.cn/projects/tulou-collective-housing. Accessed on: 15 Apr. 2016.

[17] Yiping, D., Will Wang Shu's village be nothing but an imagined form of rural life for urbanites? Architectural Review, 2015. www.architecturalreview.com/today/will-wang-shus-village-be-nothing-but-an-imaginedform-of-rural-life-for-urbanites. Accessed on: 10 May 2016.

[18] Cattaneo, T. \& De Lotto, R., Rural-Urbanism-Architecture. Design Strategies for Small Towns Development, Alinea Editrice: Firenze, p. 160, 2014.

[19] Groat, L. \& Wang, D., Architectural Research Methods, 2nd ed., John Wiley: Hoboken, p. 309, 2013. 